\title{
O trigo e o joio: segredos e botânica médica em Goa, c. $1840-1930$
}

The Wheat and the Chaff: Secrets and Medical Botany in Goa, c. 1840-1930

Le grain et l'ivraie: secrets et botanique médicale à Goa, c. 1840-1930

\section{Ricardo Roque}

\section{OpenEdition}

\section{Journals}

Edição electrónica

URL: http://journals.openedition.org/rccs/7019

DOI: $10.4000 /$ rccs.7019

ISSN: 2182-7435

\section{Editora}

Centro de Estudos Sociais da Universidade de Coimbra

Edição impressa

Data de publição: 1 Maio 2018

Paginação: 113-136

ISSN: 0254-1106

\section{Refêrencia eletrónica}

Ricardo Roque, "O trigo e o joio: segredos e botânica médica em Goa, c. 1840-1930 》, Revista Crítica de Ciências Sociais [Online], 115 | 2018, colocado online no dia 15 maio 2018, criado a 02 maio 2019. URL : http://journals.openedition.org/rccs/7019; DOI : 10.4000/rccs.7019 


\section{RICARDO ROQUE}

\section{O trigo e o joio: \\ Segredos e botânica médica em Goa, c. 1840-1930*}

Neste artigo explora-se a dinâmica de pesquisa e transformação de saberes médicos vernaculares indianos por praticantes da medicina Ocidental em Goa entre 1840 e 1930. Através de uma descrição do efervescente campo da botânica médica nesta antiga colónia portuguesa, o artigo contribui para um recentramento das histórias do orientalismo botânico português, deslocando o enfoque cronológico do século XVI para o século XIX. Argumenta-se que este campo orientalista sobre plantas e saberes indígenas assentou numa estratégia de tradução científica, a um tempo sociopolítica e epistémica, com dois movimentos conexos: o trabalho de incorporação de conhecimento médico-botânico indígena (os chamados segredos) foi acompanhado por um trabalho político de subordinação e exclusão profissional dos seus praticantes indígenas originais.

Palavras-chave: botânica médica; farmacologia; orientalismo; tradução científica.

\section{Introdução}

Quem se referir ao lugar dos portugueses na história universal da ciência e da medicina dificilmente evitará uma menção ao médico Garcia da Orta e ao seu lendário livro Colóquios dos simples e drogas da Índia, publicado em Goa, em português, no ano de 1563. Um e outro são marcos ilustres no imaginário dos tempos dourados das Descobertas, que um insistente vocabulário nacionalista e muita da historiografia da Expansão nos habituou

\footnotetext{
* Agradecimentos: este artigo é resultado dos projetos "Medicina tropical e administração colonial" (POCTI/ANT/41075/2001) e "Medicina colonial, estruturas imperiais e vidas pós-coloniais em português" (POCTI/PLUS/ANT/15157/1999), coordenados por Cristiana Bastos no Instituto de Ciências Sociais da Universidade de Lisboa (ICS-ULisboa) e financiados pela Fundação para a Ciência e a Tecnologia, entre 1998 e 2002. Beneficiou também do convénio ICS-ULisboa/Casa Oswaldo Cruz "Saberes médicos e práticas terapêuticas nos espaços de colonização portuguesa" (IICTI-GRICES/CNPq). Agradeço a Cristiana Bastos e Mónica Saavedra o companheirismo e diálogo intelectual que esteve na origem deste texto e os comentários a versões iniciais; e a Rochelle Pinto e aos avaliadores anónimos da RCCS pela leitura atenta e comentários que muito contribuíram para a versão final.
} 
a olhar como referente privilegiado da história nacional (cf. Gouveia, 1985; Henriques e Margarido, 1989: 119-148; Ferrão, 1992; mas, para a historiografia mais recente sobre Orta no contexto do século Xvi, ver e.g., Carvalho, 2013, 2015; Costa, 2015). Assim uma convicta historiografia nacional tem feito de Orta e dos Colóquios uma demonstração categórica do pioneirismo experimental dos portugueses; um anúncio precoce dos pilares da revolução científica no Ocidente, revelando pela primeira vez ao "velho mundo" os poderes de plantas e saberes curativos escondidos nas misteriosas culturas médicas do Oriente. ${ }^{1}$ Nestas perspetivas, parece certo que caso se queira atender àquilo que os portugueses e o seu império ofereceram à grande narrativa da conquista científica do mundo, em especial do exótico Oriente, há que viajar até à Goa dourada dos séculos XVI e XvII. Depois, ou assim parece, pouco mais ficará por contar.

Este texto, portanto, dificilmente poderia ter outro ponto de partida; mas não terá o mesmo ponto de chegada. Proponho deslocar a história da botânica médica contada em torno de Orta e dos Descobrimentos para outro tempo, ainda que no mesmo lugar: Goa, colónia na periferia do "terceiro império" na segunda metade do século XIX e inícios do século XX. Através de uma descrição da botânica médica em Goa, o artigo contribui assim para um recentramento das histórias do orientalismo botânico português, deslocando-as do século XVI para o século XIX. O texto tem como referência as atividades dos praticantes de medicina associados à mais importante instituição de ensino médico no espaço colonial português: a Escola Médica ou Médico-Cirúrgica de Goa, fundada em Goa em 1842, e cujas várias gerações de diplomados em medicina desempenharam um papel fulcral nos serviços de saúde do império, não só na Índia, como nas restantes colónias da Ásia e África portuguesa (Bastos, 2001a, 2001b, 2007a). Se parece certo o impacto de Orta e dos Colóquios nas comunidades ilustradas da Europa, atendendo à circulação da sua versão latina logo em 1567, reeditada e traduzida em francês e italiano, já menos se sabe sobre o que interessa reter da sua circulação nos séculos seguintes (cf. Gouveia, 1985: 23-25; Mathew, 1997: 376). Não obstante a obra de Orta ter aparecido na Goa do século XVI, é a sua segunda vida no século XIX que aqui me interessa. E interessa-me sobretudo o campo que despertou o autor para essa segunda vida, tornando-o objeto de leitura e comentário e reinventando-o enquanto ícone de uma área distinta de pesquisa. Com efeito, como se verá, o resgate genealógico do trabalho de Orta como legitimação fundadora de um campo

${ }^{1}$ Compare-se Gaitonde (1983), Mathew (1997), Almeida (1999), Porter (1999: 144-145) e Walker (2001). 
de estudos científicos de botânica indiana e colonial é um produto tardio da segunda metade do século XIX. É neste período, portanto, em particular na década de 1890 e nos primeiros anos do século Xx, que podemos situar a insinuação de um orientalismo médico-botânico goês, protagonizado por médicos locais, quase todos filhos de Goa.

Terá sido nesse contexto que a obra de Orta, após longo tempo praticamente votada ao desinteresse pelas audiências académicas portuguesas, foi recuperada por estudiosos da botânica ultramarina. Na metrópole, a ressurreição do trabalho de Orta surgiu em pleno caldo ideológico do nacionalismo imperial e do despertar das ciências naturais. Uma tradução da versão latina para língua portuguesa apareceu em 1891, por iniciativa da Academia Real das Ciências e dirigida e anotada pelo Conde de Ficalho (Ficalho, 1891). O bom acolhimento do público justificou uma segunda edição $\operatorname{logo}$ em 1895 e, em 1913, surgiria em Londres a tradução britânica. Nova edição metropolitana sairia apenas em 1964, pela Junta de Investigações do Ultramar, a título de comemoração do quarto centenário da edição original dos Colóquios (Clúsio, 1964; Mathew, 1997: 376). $\mathrm{O}$ interesse metropolitano coincidia com um interesse paralelo, acerca das plantas e saberes indianos, em Goa. Assim, de forma algo independente das traduções metropolitanas, também o trabalho de Orta motivava entusiasmos na comunidade médica goesa no final do século XIX. No mesmo ano de 1891, um dos pioneiros da botânica goesa, Gelásio Dalgado, publicava em Bombaim, "sem ter conhecimento", dizia, da tradução dos Colóquios pelo Conde de Ficalho, uma classificação das plantas e drogas descritas na obra de Orta (Dalgado, 1894, 1898). ${ }^{2}$ Na verdade, das palavras de Dalgado depreende-se que o seu interesse nos Colóquios comunicava mais diretamente com dinâmicas locais, em Goa, do que com dinâmicas metropolitanas (vd. também Teles, 1862; Dalgado, 1898: v).

Mas o envolvimento goês na investigação botânica ia bem além da ressurreição arquivística de antigos estudos. Como espero demonstrar, tal envolvimento expressava um investimento coletivo no estudo das plantas medicinais e em nova investigação de segredos e saberes médicos das culturas indianas. Fora do escopo do presente trabalho, embora conexos aos processos aqui examinados, encontram-se processos de circulação de plantas goesas e europeias entre Portugal e Goa, quer para constituição de coleções "científicas" botânicas, quer para usos comerciais

${ }^{2} \mathrm{O}$ trabalho de Orta, escrito no século XvI, implicava igualmente uma tradução do estilo literário. Sobre a importância do estilo narrativo da ciência do tempo de Orta, veja-se Leitão e Sánchez (2017). 
e até terapêuticos. ${ }^{3}$ Com efeito, como mostrou Timothy Walker (2010), a disseminação de drogas e medicamentos indianos, por iniciativa de autoridades médicas em Goa, para a metrópole e para espaços atlânticos foi uma prática corrente entre meados do século XVII e o início do século XIX. Por seu turno, o orientalismo médico-botânico de que aqui trato diz respeito às iniciativas locais que tomaram forma em Goa, decorrentes de iniciativas múltiplas animadas pelos profissionais saídos da Escola Médica de Goa. Ademais, atendendo à ampla circulação dos profissionais médicos formados por esta Escola por outros espaços do império português ao longo dos séculos XIX e XX, como assinalou Cristiana Bastos (2001b), é de crer que o tipo de abordagem integradora dos saberes nativos experimentado em Goa possa ter tido repercussões noutros lugares. Nas colónias africanas sobretudo, como também sugere Bastos, o estilo de interação com os saberes médicos nativos, fluido e tendencialmente hibridizante, dos antigos profissionais da Escola, coabitou com a crescente influência de formas mais hierárquicas e intolerantes da biomedicina na relação com os saberes locais a partir de finais do século XIX (Bastos, 2007b). Este texto resume o seu enfoque a Goa e ao significado, nesse contexto, das práticas de investigação da botânica indiana e dos saberes nativos a ela associados; descreve, assim, um género de orientalismo botânico, emergente em Goa no século XIX, protagonizado por médicos associados à referida Escola Médica - mas ainda pouco explorado pela historiografia.

Procuro dar aqui unidade à exploração abrangente deste género de saber orientalista usando a ideia de "tradução". A partir do caso de Goa, proponho explorar o orientalismo - em sentido amplo, enquanto campo de práticas de saber centrado na objetivação daqueles e daquilo que define o, ou pertence ao, "Oriente" - não como uma dinâmica monológica de espelho onde importam somente os códigos, princípios, e elementos do "discurso" ocidental (como na clássica formulação de Said, 2004 [1978]), mas antes como dinâmica de tradução - na qual materiais com origem nas diferentes formações culturais postas em contacto no encontro colonial são consequentes para a forma e para os conteúdos do produto "ocidental" final - na qual os elementos de origem reaparecem em novos arranjos. No que respeita à ciência e à medicina, a noção de tradução tem sido reinventada nos estudos sociais da ciência como instrumento analítico. A partir desta lente, a atividade de produção científica vem emergindo como processo, a um tempo discursivo e material, de recomposição de elementos heterogéneos

\footnotetext{
3 Gracias (1994: 172), por exemplo, encontrou nos arquivos da família de negociantes Mhamai registos da circulação de plantas de valor medicinal de Goa para Portugal, algures entre o século XVIII e inícios do século XIX.
} 
(por exemplo, pessoas, coisas, interesses, inscrições) em arranjos inéditos de relações (cf. Latour, 1995). Investigo aqui esta ideia de tradução científica para descrever o trabalho coletivo protagonizado por praticantes da medicina de estilo ocidental ${ }^{4} \mathrm{com}$ vista não apenas a conhecer mas a rearranjar saberes e objetos em uso nas medicinas indianas em saberes e objetos terapêuticos da medicina ocidental. Centrar a atenção na dinâmica de tradução de saberes e medicamentos indígenas no quadro da ciência médica pode permitir também surpreender as hesitações e novidades dos processos e "modos de invenção", contrariando a imagem da produção científica de medicamentos como acontecimento apoteótico de descoberta, ou como resultado da pura ação de uma "farmacologia racional" (Pignarre, 1993). Este texto não procura explorar em profundidade as potencialidades desta perspetiva, que pode ser acompanhada e confrontada pelo menos em dois estudos de caso, um trabalho anterior relativo à medicina goesa (Roque, 2004) e o estudo de Hsiang-lin Lei (1999) sobre a medicina chinesa. Na sequência desses trabalhos, tentarei aqui sugerir a existência de um orientalismo de tradução, apresentando os princípios gerais e as principais estratégias sobre os quais assentou a sua emergência em Goa nos séculos XIX e XX. Argumenta-se que este campo orientalista sobre plantas e saberes indígenas assentou numa estratégia, a um tempo política e epistémica, de tradução com dois movimentos: o trabalho de incorporação de conhecimento médico-botânico indígena era acompanhado de um trabalho de subordinação e exclusão profissional dos seus praticantes indígenas originais. O texto divide-se em três partes principais. Uma primeira parte trata dos agentes, objetos, instituições e fronteiras do campo. Uma segunda parte dirige a atenção para o programa da tradução científica de segredos e plantas medicinais em medicamentos científicos; por fim, a partir de alguns episódios, procuro apontar as principais técnicas e estratégias políticas e científicas de tradução.

\section{O mito das plantas medicinais e a botânica médica oitocentista}

Ninguém ignora que este país abunda em plantas medicinais que nos são desconhecidas. Os curandeiros as aplicam aos doentes gentios, que rejeitam a nossa terapêutica,

\footnotetext{
${ }^{4}$ Ao longo deste texto, utilizo a expressão "medicina ocidental" como sinónimo da tradição médica alopática emergente na Europa Ocidental. No contexto histórico deste estudo, a medicina de estilo ocidental em Goa era praticada dominantemente por grupos de nativos goeses, sendo estes aliás protagonistas da interação com as ditas "medicinas indígenas" indianas. Utilizo aqui as expressões "medicinas indígenas" em obediência às designações da época, que de modo geral tratavam indiferenciadamente outras formas de medicina não-ocidental em Goa. Assim, quando não qualificado pelos próprios atores, essa expressão poderá designar vários estilos de medicina - ayurveda, yunani, tradições populares, etc.
} 
e nem sempre deixam de obter bons resultados. Fala-se em curas milagrosas, e que estão fora do alcance da medicina europeia. [...] Conhecer e tornar públicas as plantas indígenas, e seus efeitos medicinais; fazer conhecidas de todos as plantas, e remédios profícuos, que são hoje propriedade de poucos, e que como objetos de segredo são por isso vendidas a grandes preços; enriquecer enfim a ciência, e bem fazer à humanidade enferma: são os fins que a Junta de Saúde pretende conseguir. (Torres e Oliveira, 1871 [1848]: s.p.)

Estas palavras foram proferidas pelos físico e cirurgião mores do Estado da Índia, os portugueses Francisco da Silva Torres e José António Oliveira, poucos anos após a criação da Escola Médica de Goa. Eram dirigidas ao Governador Geral do Estado da Índia e apelavam à investigação aprofundada de drogas e plantas medicinais indígenas como via para a cura das moléstias locais. Elas contêm as marcas daquela que pode tomar-se como a ambivalência estruturante do discurso dos arautos da medicina europeia acerca dos saberes, práticas e praticantes indígenas ao longo do século XIX e inícios do século xx. O espectro do perigo do curandeirismo e o endurecimento do controlo dos saberes locais parecia acompanhar-se, no seu reverso, por um fascínio pelo estudo quer da flora oriental, quer do conhecimento indígena acerca da sua administração terapêutica, que se percecionava existir na posse dos praticantes de medicinas indianas. ${ }^{5}$ Para os médicos ocidentais, irmanados em torno da Escola Médica de Goa, apropriar-se da chave para um mundo de fantásticas promessas terapêuticas equivalia, em grande medida, a dominar o conhecimento e o uso medicinal das plantas indianas. Mas agir sobre as plantas significava também vencer a batalha pela autoridade profissional. O poder dos praticantes indígenas julgava-se residir no monopólio da administração terapêutica e do conhecimento farmacológico das plantas, ameaçando a todo o momento a pretensa superioridade da medicina ocidental.

Agir sobre as plantas significava igualmente atuar na resolução da luta pelo controlo das mortíferas moléstias locais, perante as quais as terapêuticas ocidentais se viam frequentemente impotentes - e cuja forma de cura, acreditavam muitos, se encontrava algures ignorada na ecologia natural da Índia ou nas receitas secretas dos "curandeiros" indianos.

\footnotetext{
${ }^{5}$ O discurso dos médicos de estilo ocidental tendia a homogeneizar a diversidade das medicinas locais. Em todo o caso, a centralidade das plantas na prática médica da medicina hindu (em particular na farmacopeia ayurvédica) parece ser incontestável (cf. Zimmermann, 1989: 18). Sobre as transformações da tradição ayurvédica na sua interação com a tradição médica ocidental no século XIX, veja-se Mukharji (2016).
} 
'[O] que é do país', dizia Neri Correia em 1925, 'deve convir melhor às moléstias e aos doentes desta terra, do que as drogas que nos vêm do estrangeiro, salvo quando a sua fabricação se adapte rigorosamente às variantes do clima de cada região e aos hábitos de cada país, o que parece assaz problemático’. (Correia, 1925: II)

Mas como fazer para dar à medicina ocidental o domínio sobre o mundo vegetal que parecia ser monopólio indígena? Pode dizer-se que o apelo de Torres e Oliveira continuaria a ecoar em Goa, intermitentemente, ao longo das décadas seguintes: era preciso explorar a natureza, conhecer cientificamente o mundo vegetal. A representação da flora indiana como envolta em mistério e sítio de abundantes e milagrosas revelações medicinais constituiu um traço estruturante do imaginário médico de Goa. Ao imaginário centrado nas virtudes das plantas medicinais goesas juntava-se a esperança de localizar na flora local a chave do desenvolvimento económico colonial. ${ }^{6}$ Os "tesouros terapêuticos escondidos na nossa flora”, na expressão do médico Miguel Caetano Dias (1902), tornaram-se, pois, ao longo do século XIX e primeira metade do século Xx - embora, como se verá, de forma dispersa - o objeto central de um labor científico, botânico, farmacológico e experimentalista. E é da descrição de algumas dessas tentativas que tratarei de seguida.

\subsection{Botânica e farmacologia na Goa oitocentista}

A recuperação do trabalho do famoso médico quinhentista Garcia da Orta em meados do século XIX é sinal do labor atrás referido. Porém, em comparação com a Índia inglesa (constante referência e modelo para os médicos goeses oitocentistas), o estado dos estudos da flora medicinal goesa permanecia, na viragem para o século xx, pouco encorajador. Assim entendia o goês Viriato João Pinto, cujo interesse pela farmacopeia indiana se firmara no contacto com os especialistas ingleses, de quem fora discípulo em Bombaim. Tomando justamente como referência a escassez de leitores e comentadores da seminal obra de Orta, escrevia em 1909: "Tristeza, porém, é ter de reconhecer que o que Garcia da Orta e outros haviam escrito, só raros em Portugal conhecem em dias de hoje, além do completo desconhecimento que sobre tais escritos pesa" (Pinto, 1909: 362). De facto, coube aos ingleses o primeiro e mais sustentado esforço de exploração botânica e farmacológica da flora indiana. Em seu torno constituiu-se um campo orientalista de estudos das medicinas indianas, cuja tentativa mais

\footnotetext{
${ }^{6}$ Não quer dizer que este mito do carácter milagreiro das plantas da medicina indígena fosse isento de oposição - o que, aliás, reforça talvez a ambiguidade do discurso médico sobre os saberes indígenas (cf. por exemplo Cardoso Jr., 1902: 185-191; Miranda, 1911: 499-503).
} 
assinalável partiu do orientalismo sincrético das décadas de 1820 e 1830, com diversas traduções de clássicos das medicinas ayurvédica (a tradição védica hindu centrada no equilíbrio holístico do organismo) e unani (a antiga tradição médica de raízes gregas, asiáticas e persas centrada na ideia de humores), bem como o sucessivo aparecimento de sistematizações taxonómicas e farmacológicas em materias medicas da Índia ao longo do século XIX (cf. Sangwan, 1992; Arnold, 1993: 43-58; Bayly, 1996; Leslie, 1998). Assim, em Goa, os investigadores tomavam como referência fundamental os anteriores trabalhos dos médicos e botânicos na vizinha Índia inglesa, promovendo-os, de forma explícita, como exemplo a seguir no estudo da flora local (Pinto, 1909: 362; Dalgado, 1898).

O conjunto das monografias de botânica goesa publicado neste período, quer em Goa, quer na metrópole, é revelador de várias iniciativas individuais relativamente dispersas. Estas parecem ter carecido de enquadramento e apoio institucional, mas a sua manifestação variada constitui evidência de uma farmacologia botânica que ganhava espaço visível na esfera pública de Goa. A década de 1890 mostrou-se, assim, fértil em esforços, apelos, e publicações variadas. Em 1895, Lencastre Pereira de Andrade publicou em Margão os seus estudos botânico-farmacológicos (a que se seguiria novo trabalho em 1899) em que precedia o seu trabalho de uma extensa apologia da utilidade da ciência botânica para o progresso geral da colónia de Goa (Andrade, 1895, 1899, 1929). Reiterando o mito milagreiro do mundo vegetal goês, Andrade incitava ao desenvolvimento de novas pesquisas, pois, escrevia, sobretudo ao médico "o conhecimento das plantas torna-se indispensável [...] para combater um grande número de doenças" (Andrade, 1895: vii-viii).

Em sintonia com o ideário botânico de Andrade, publicavam-se em 1898 os trabalhos de Gracias e Dalgado (o primeiro, em Margão; o segundo, em Lisboa) (Dalgado, 1898; Gracias, 1898). Ambos se apresentavam como "obras comemorativas", associando-se simbolicamente à comemoração do quarto centenário da chegada de Vasco da Gama à Índia. Esta associação conferia-lhes um marcado cunho patriótico, numa época em que o nacionalismo imperialista português estava ao rubro. Dalgado recebera o apoio da Comissão Central do centenário para enveredar num projeto de botânica geral da província indiana; Gracias ganhara o subsídio do governo provincial de Goa para apresentar um mais comedido e pragmaticamente orientado inventário de produtos de combate às febres da região. Porém, para estes dois autores, tal como para Andrade, tratava-se de construir um inventário botânico e farmacológico das drogas naturais da Índia. Ou seja, tratava-se de tentar uma combinação de métodos, usando o estilo literário 
do catálogo e do inventário. Por um lado, adotava-se a classificação lineana, sistemática, arrumando as plantas na ordem natural dos vegetais. Por outro lado, mostrava-se um esforço para associar a botânica clássica aos princípios da nascente farmacologia laboratorial, na esteira da química moderna de Lavoisier, quer tentando descortinar, quando possível, os princípios ativos, os efeitos e a composição química das plantas, quer ensaiando uma codificação, dir-se-ia, tecnológica dos usos e modos de administração habituais - a chamada discriminação das "propriedades e usos" terapêuticos da planta.

\subsection{A formação de uma esfera pública: os periódicos}

$\mathrm{O}$ apoio oficial a estas iniciativas botanicofarmacológicas parece ter ficado por aqui, bem como a visibilidade monográfica de trabalhos do mesmo género. Até nesses casos, a participação das instituições da administração colonial ter-se-á resumido a um incentivo para publicação, com objetivos episódicos de comemoração ritual. Os políticos imperialistas, que não os médicos ultramarinos no exercício da sua profissão, pareciam desinteressados do projeto de inventariação de plantas e terapêuticas nativas. Os trabalhos de Dalgado, Gracias e Andrade decorreram da iniciativa particular dos autores, fruto de um labor de anos seguidos de recolha e observação concomitante com o exercício da profissão de médico ultramarino. $\mathrm{Na}$ verdade, este retrato de iniciativa privada e de descontinuidade de projetos cujo interesse parecia estar limitado à profissão do médico colonial pareceu refletir-se também no conjunto de notícias farmacológicas e botânicas que encontrei. Estes registos aparecem em capítulos de obras de viajantes - caso dos famosos apontamentos do agrónomo Lopes Mendes (1991 [1886]: 107-109); ver também Cardoso Jr. (1902: Xv, 177-191). Mas, sobretudo, essas "notícias" proliferam, dispersas, pelo universo de revistas de medicina e farmácia que, na Goa da segunda metade do século XIX, animou de forma inédita um circuito de redação, publicação, leitura e debate público sobre plantas, terapêuticas e medicamentos indígenas, a saber: o Jornal de Pharmacia e Sciencias Medicas da India Portugueza (1862-1863) e o Archivo de Pharmacia e Sciencias Acessorias da India Portugueza (1864-1870), ambos editados pelo farmacêutico António Gomes Roberto; o Jornal de Pharmacia Chimica e Historia Natural Medica, que lhe deu seguimento em 1871, editado pelo farmacêutico João Herculano Moura; o Arquivo Médico da Índia (1894-1896); e, mais tarde, o Boletim Geral de Medicina e Pharmacia (1912-1919), cuja secção farmacêutica esteve a cargo de Francisco da Silva Amorim.

As palavras de Gomes Roberto no prospeto com que abria em 1862 o primeiro desses periódicos farmacêuticos, o Jornal de Pharmacia, convocava 
a classe dos médicos da Índia para a tarefa coletiva de "esclare[cer] acerca dos sintomas e tratamento das doenças especiais do país, [...] e bem assim, [dar]-nos um conhecimento amplo do emprego e virtudes, de muitas plantas privativas do país [...]" (Roberto, 1862: 1). Semelhante propósito continuava a animar o Jornal de Pharmacia, Chimica e Historia Natural Medica, continuador da publicação dirigida por Gomes Roberto. $\mathrm{Na}$ apresentação do Jornal, em 1872, Herculano Moura, farmacêutico do quadro e regente da cadeira de farmácia da Escola Médica de Goa, reincidia no apelo à divulgação, nesse jornal, de "tudo o que encontrarmos interessante com respeito à farmacologia, não esquecendo a hindu; dando conhecimento de qualquer composição ou substância medicamentosa das usadas na medicina popular com reconhecido proveito; [...]" (Moura, 1872a: 1).

Formava-se assim um género de esfera pública médico-farmacêutica, assente em publicações que envolviam uma comunidade de leitores e observadores da flora medicinal indígena e das suas experimentações terapêuticas. Para lá das monografias, pode assim apreciar-se a vivacidade desse processo coletivo de "descoberta" e apropriação da flora indiana e dos saberes locais através da proliferação de pequenas notícias e curtos registos (sob rubricas como "estudos de farmacologia indiana", "variedades" ou "terapêutica") nos periódicos médico-farmacêuticos. Do mesmo modo, é possível antever esse dinamismo em manuscritos e correspondência oficial, nomeadamente nos relatórios dos chefes do Serviço de Saúde - como o de Miguel Caetano Dias, que, em 1902, incluía no seu relatório um catálogo das "Plantas medicinais mais conhecidas e que se encontram em maior ou menor abundância nos diversos concelhos de Goa, e em uso pelos empíricos" (Dias, 1902). Os protagonistas deste processo coletivo de publicação e "divulgação" foram, em geral, os comuns médicos coloniais que, exercendo clínica no interior da província, se dedicavam ao estudo das plantas e sua aplicação clínica. Foi por certo dando seguimento a este processo coletivo que, como se verá de seguida, alguns médicos se esforçaram por elevar a "farmacologia indiana" ao estatuto de matéria obrigatória nos currículos da Escola Médico-Cirúrgica de Nova Goa, nas décadas finais do século XIX (cf. Bastos, 2001a).

\subsection{A medicina indiana na Escola Médica de Goa}

Sinal da ligação do projeto inicial de investigação das plantas medicinais à Escola de Goa foi o facto de os editores dos primeiros periódicos de farmacologia - Gomes Roberto, Herculano Moura e Silva Amorim - serem lentes na instituição, ainda que farmacêuticos de origem portuguesa formados na metrópole. Porém, um dos mais acalorados defensores do ensino de botânica médica e farmacológica no quadro da Escola, bem como da revitalização 
orientalista goesa do ayurvedismo no século XIX, seria o goês Viriato João Pinto, médico e professor (jubilado em 1913). A ele se devem tomadas de posição inflamadas a favor da integração de plantas e saberes indígenas nos currículos da Escola, tradicionalmente restritos ao cânone médico ocidental (vinham quase decalcados dos currículos médicos na Europa, em particular das universidades e escolas médicas metropolitanas em Portugal). O final do século XIX assinala uma mudança na exclusão institucional de outras formas de conhecimento, no sentido de um orientalismo de referência europeia e, em particular, britânica. $\mathrm{Na}$ verdade, por essa altura assiste-se em Goa ao surgimento de um interesse positivo (ainda que porventura assente em visões etnocêntricas ou decadentistas das tradições hindus) pela investigação dos textos da tradição erudita da medicina ayurvédica (Pinto, 1909; Barcar, 1912). Foi neste tom que, em 1887, Viriato João Pinto concluiu o seu discurso inaugural na sessão solene de abertura do ano letivo na Escola:

Concluindo desejo chamar-lhes a atenção a um estudo que por circunstâncias especiais da terra adquire maior importância, a botânica médica. [...] O médico porém toma nesse estudo [botânico] um outro interesse; o reino vegetal fornece-lhe a maior parte dos agentes terapêuticos. [...] Seria desejável, seria a realização de uma grande aspiração que esta escola formasse médicos, que na África ou na Índia, na falta de recursos farmacêuticos, longe de se conservarem desarmados à cabeceira do enfermo, corressem a colina ou vale, o prado ou a floresta para pedir ao reino vegetal, auxiliares com que se alivie os sofrimentos dos padecentes. (Pinto, 1887: 21-23)

Pinto não foi o único docente da Escola Médica a declarar a importância de apoio institucional ao ensino e estudo da botânica médica indígena, e bem assim à sua integração no arsenal terapêutico dos médicos ultramarinos. Poucos anos mais tarde, no seu relatório anual, o chefe do Serviço de Saúde, Miguel Caetano Dias, apelou à criação de "um horto botânico de plantas medicinais indígenas, anexo à Escola de Nova Goa, pois sabe-se que a flora indiana possui importantes tesouros terapêuticos" (Dias, 1902). A crer nas palavras desconsoladas de Pinto, mais tarde, tal projeto de criação de um jardim de plantas ficou votado ao fracasso (Pinto, 1909: 372). Em todo o caso, a evidência documental sugere que a Escola preservava, até ao início do século Xx, a coleção de plantas nativas organizada, para fins pedagógicos e de estudo, pelo célebre chefe do Serviço de Saúde do Estado da Índia, João Stuart da Fonseca Torrie. Nas décadas de 1870 e 1880, Fonseca Torrie empenhara-se no estudo das plantas e dos saberes indígenas e desse trabalho resultou a sua coleção de botânica médica; salvo raras exceções em documentos oficiais, as suas notas de estudo botânico ficaram, na maioria, 
inéditas (cf. Torrie, 1879; Pinto, 1887: 22-23). O próprio Pinto, aliás, queixar-se-ia da mesma invisibilidade em relação ao seu próprio trabalho. Por sua iniciativa, enquanto ensinou "Materia Medica e Farmácia" na Escola de Goa entre 1903 e 1905, ministrou aos seus alunos "uns apontamentos" de botânica médica, servindo-se da coleção de Torrie (Pinto, 1909: 376). Mas acabaria por se inibir de publicar o manuscrito "Medicamentos eficazes e experimentados", onde reunia o resultado de anos de estudo de segredos e medicamentos (ibidem: 362). Não obstante estas iniciativas dos docentes, formalmente, o programa da Escola permaneceria inalterado no que respeitava a essas matérias. Em 1927, Froilano de Melo proporia ainda a criação, pela "primeira vez", de uma cadeira de História da Medicina Ayurvédica, bem como de "um laboratório e mostruário das mais importantes drogas e preparados da medicina ayurvédica" (Figueiredo, 1960: 171). Contudo, o projeto não parece ter sido implantado na instituição.

Apesar do efervescente orientalismo médico-botânico, as modificações institucionais custavam a acontecer e, nos anos seguintes, os apelos à reforma curricular e à renovação da coleção de Torrie suceder-se-iam, sem êxito aparente (cf. Sá, 1920; Barreto, 1948). Mas nem por isso o interesse pelo conhecimento médico indiano e pelos chamados segredos indígenas deu sinais de esmorecer no espírito de muitos. Para lá do quadro institucional do ensino e do Serviço de Saúde, é nas práticas de tradução científica de plantas medicinais e saberes locais que melhor podemos observar o orientalismo botânico em ação em Goa.

\section{Os segredos e o programa de tradução científica}

A ideia do "misterioso" poder medicinal da Índia não se circunscrevia ao mundo vegetal. Envolvia os saberes dos médicos indianos. A este corpo de conhecimento terapêutico, os médicos de Escola de Goa referiam-se genericamente como segredos. No imaginário desses praticantes, os segredos constituíam o poderoso e inacessível conhecimento da administração das plantas possuído pelos praticantes das medicinas autóctones, cuja definição parecia ser capaz de incluir quer os saberes mais codificados dos praticantes ayurvédicos, quer terapêuticas de raiz mais popular. Para muitos médicos coloniais, a medicina indígena albergava tanto de supersticioso, mágico, primitivo e selvagem quanto de incompreensível e maravilhoso nos seus efeitos terapêuticos. Convivia a perseguição ao "curandeirismo" com o fascínio e a investigação interessada por esse mesmo universo terapêutico. $\mathrm{Na}$ verdade, havia curandeiros e curandeiros, havia boas e más terapêuticas. Isto é: tratava-se de saber distinguir entre aquilo que eram meros produtos de um suposto empirismo irracional e o que a ciência podia reconhecer 
como efetivos remédios - tratava-se de encetar uma verdadeira e racional reforma e reavaliação da experiência indígena, quer dos antigos textos clássicos hindus, quer de atuais artes de curar (Roberto, 1864). Ao mesmo tempo, importava excluir dos poderes das plantas e dos segredos os antigos detentores: os praticantes indígenas. Nas palavras de Viriato João Pinto, em 1909, era necessário: "Saber distinguir o trigo do joio; procurar não ser cego ao que uma experiência, muitas vezes centenária, nos indica [...]" (Pinto, 1909: 378). Só assim a medicina racional ganharia a batalha sobre o curandeirismo e os herbolários. Concluía Pinto:

Creio que, com o estudo e o emprego racional das mesmas substâncias, acabaríamos de vez e sem violência alguma, toda a ervanária nativa; visto que todos os que tivessem fé nas substâncias ministradas pelos herbolários como segredos, viriam a recorrer de preferência aos médicos desta Escola [Médica de Goa], por neles encontrar toda a superioridade, são conhecimento e razão, que os guiaria no uso dos medicamentos nativos. (Pinto, 1909: 378)

\subsection{A exclusão dos "charlatães" e dos praticantes das medicinas indianas}

Como a passagem anterior indica, não é possível dissociar o interesse pela investigação das plantas medicinais e dos segredos da estratégia profissional de afirmação de autoridade por parte dos representantes da Escola Médica de Goa. Compõem, em conjunto, um mesmo esquema de tradução científica. A implantação da medicina e da farmácia ocidentais está fortemente associada à criação da Escola Médico-Cirúrgica de Goa, que iniciou a sua atividade em 1842, mas que obteve reconhecimento do poder central apenas em 1847. A ela se deveu a formação de um corpo profissional de médicos e farmacêuticos locais, de recrutamento fundamentalmente nativo, com papel decisivo nesse processo. À Escola vieram associar-se, a partir da década de 1860, como se viu, uma série de publicações especializadas nos assuntos de medicina, farmácia e história natural goesas, sinais de um processo de formação de uma identidade profissional que teve um dos seus momentos fortes na criação da Associação Médico-Farmacêutica da Índia Portuguesa, em 1913. Com o desenvolvimento da Escola, assistiu-se a um reforço do controlo sobre o exercício de medicina e farmácia, quer reservando aos diplomados pela Escola de Goa o acesso direto à legitimidade do exercício da profissão médica no território, quer centralizando na autoridade da Junta de Saúde a concessão de licenças para a venda de medicamentos e para a prática de medicina. Nesse sentido, logo em 1842, foi publicada no Boletim do Governo do Estado da Índia a regulamentação para a preparação e comercialização de medicamentos, precisamente com o intuito de impedir 
a manutenção e proliferação dos ditos "herbolários", bem como dos seus segredos e medicamentos. Esta regulamentação estipulava, entre outros aspetos, "Que ninguém, que não seja Boticário habilitado, e com licença, possa vender ou preparar medicamentos"; "Que nenhum Boticário possa vender remédios sem que sejam receitados por pessoa legitimamente autorizada, nem remédios de segredos sem licença competente" (Moacho, 1842:341).

A afirmação da autoridade dominante dos médicos de estilo ocidental implicava um discurso duro de demarcação num espaço de concorrência com especialistas autóctones de medicinas indianas, numa clara estratégia de autoridade profissional que tendia a excluir do acesso legítimo ao exercício da medicina aqueles que não eram credenciados pela Escola e pelo Estado colonial. Para as autoridades médicas em Nova Goa, o recurso persistente da população aos especialistas indígenas, e mesmo a sua proteção por alguns filhos da Escola, constituía um problema crucial de saúde pública. A multiplicação de "charlatães", "herbolários" ou "mezinheiros" parecia incontrolável e ameaçava inquinar o correto exercício da medicina por alguns médicos e farmacêuticos treinados na Escola de Goa e dispersos pelo território, que com facilidade atravessavam as fronteiras das suas atribuições (vd. Moura, 1872b: 161-162).

Não obstante os esforços de controlo na concessão de diplomas, no inquérito estatístico, ou na contenção punitiva, a proliferação de praticantes permanecia estrutural à sociedade goesa ao longo do século XIX. O tom depreciativo em relação ao dito "charlatanismo" era uma constante no discurso médico sobre os saberes indígenas. Todavia, esta é apenas uma parte da história. Os praticantes indígenas oscilaram entre a imagem de perigosos "empíricos" e "charlatães", e aquela de indivíduos cujas artes eram estranhamente "maravilhosas", sendo necessário sujeitá-las por isso ao escrutínio da ciência. É que a visão desdenhosa e altiva face ao charlatanismo local que, como se viu, se inscrevia num processo de afirmação profissional, convivia nesse mesmo processo com uma imagem diametralmente oposta: a de que só os praticantes indígenas possuíam a chave para abrir os tesouros de uma flora médica rica e auspiciosa (a flora indiana). Além disso, as próprias terapêuticas indígenas - genericamente denominadas de segredos - poderiam reverter em benefício da medicina científica. É possível ver nesta duplicidade a coerência de uma estratégia de "tradução científica", assente numa dupla lógica de exclusão dos praticantes indígenas e de reconversão positiva dos saberes e objetos dos sistemas indígenas, nos termos da medicina ocidental (cf. Lei, 1999). Esta dupla estratégia de tradução assentava na delimitação de uma fronteira que os sujeitos-praticantes da medicina estavam proibidos de transpor; uma fronteira que, ao mesmo tempo, certos objetos (certas plantas 
e certos "segredos") eram incitados a cruzar, sob a condição de passagem em variados testes.

A convivência do trabalho de controlo e exclusão profissional com a tentativa de expropriação de saberes é visível em vários momentos da história do Serviço de Saúde do Estado da Índia. A tradução centrava-se, pois, na apropriação da natureza, ou da flora indiana, dos seus medicamentos, da matéria médica oriental, e na exclusão dos indivíduos, os praticantes locais, denominados de "charlatães". Só os primeiros eram aproveitáveis se dissociados dos segundos e trazidos, segundo os testes próprios à ciência, para as mãos dos profissionais da Escola de Goa (cf. Melo, 1912).

\section{Vencer o "egoísmo": estratégias de tradução}

A investigação dos segredos indígenas e das plantas medicinais conhecidas pelos hindus envolvia diferentes procedimentos de tradução científica. Uma delas, como vimos acima, materializava-se na catalogação de usos, efeitos e propriedades terapêuticas inscritas em materias medicas. Outras, porém, assumiam contornos de um conhecimento fundado no testemunho experimental, desde a formação de tribunais laboratoriais e clínicos de observação e experiência das terapêuticas indígenas à apresentação pública de relatórios dessas experiências, perante a comunidade médica. Para resgatar para o domínio público da ciência médica, por via de uma observação competente e racional, um saber detido pelos nativos, era preciso traduzir materiais, tecnologias e teorias da rede sociotécnica indígena para a rede da medicina de estilo ocidental. Mas como o fazer? Como constituir e validar os necessários cenários de testes e os necessários relatos da experiência terapêutica? Como, sobretudo quando os saberes terapêuticos nativos se apresentavam ao olhar dos médicos ocidentais na forma de um conhecimento secreto, de aparência quase inacessível?

O trabalho de tradução científica e a concretização destas condições experimentais de prova enfrentava difíceis resistências, perante as quais era preciso recorrer a estratégias adequadas (cf. Torres, 1846). A primeira dificuldade em aceder ao conhecimento indígena dito secreto era resultante dos padrões de reprodução endógena dos saberes na medicina hindu. À concorrência social entre diferentes praticantes, sobrepunha-se uma diferença entre o padrão de comunicação da experiência médica ocidental (fundado no carácter público e coletivo de um saber profissional que se transmitia e preservava de forma estandardizada, em cenários institucionais - manuais, escolas, universidades) e o padrão das medicinas indianas, que assentava numa cultura oral e na transmissão pessoal e familiar dos saberes dos vaidyas. O saber (nomeadamente da medicina ayurvédica) derivava no fundamental de mensagens contidas 
nos compêndios canónicos (a Sushruta Sambita e a Caraka Sambita); porém, "a prática do ayurveda dependia grandemente", como escreveu Roy Porter, "da tradição oral, passada de mestre para discípulo, na qual um imenso repertório de material textual memorizado era recreado de modo a adequar-se a circunstâncias particulares, ainda que permanecendo fiel ao sentido fundamental do texto" (Porter, 1999: 140; cf. Zimmermann, 1995). Segundo os observadores portugueses e goeses, a este princípio de transmissão intergeracional do saber juntava-se uma lógica de fechamento e secretismo, o princípio do segredo. O agrónomo Lopes Mendes, embora veiculando uma visão depreciativa das medicinas locais, por exemplo, reconhecia a utilidade de "muitas interessantes receitas de medicina hindu", que os seus praticantes se limitavam a transmitir de pai para filho, numa espécie de manual e receituário secretos: "Quando morre um vaizá", escrevia Lopes Mendes, "deixa a seu filho, a seu neto, ou algum parente, um livro de receitas [...] O livro de receitas serve para auxiliar a memória dos novos vaizás, e também para estes colherem dele os maravilhosos segredos de curar toda a qualidade de doença" (Mendes, 1991 [1886]: 113).

O combate para vencer o obstáculo desta diferença de modelos de transmissão de saberes e de autoridade profissional deixaria, ao longo do tempo, um lastro de veementes queixas e acusações da parte dos estudiosos das medicinas indígenas. No entender indignado de alguns investigadores de segredos, a simples divulgação dos segredos ameaçaria até, segundo crenças populares, os seus poderes terapêuticos (Souza, 1944: 55).

\subsection{Os segredos como mercadoria}

A luta para vencer o obstáculo do apelidado "egoísmo" indígena esteve associada a tentativas de captação dos praticantes indianos, quer para conseguir o testemunho direto da administração das terapêuticas, quer para ter acesso ao receituário que era passado entre gerações de médicos indianos. $\mathrm{Na}$ verdade, parecia impossível construir um conhecimento científico dos segredos sem conseguir obter, de algum modo, a participação ativa dos praticantes indígenas. Alguns indícios apontam para a passagem de segredos para os praticantes da medicina ocidental enquanto mercadoria, transacionada a troco de dinheiro ou outras recompensas. É esta pelo menos uma das modalidades mais noticiadas nas fontes documentais.

Os físicos-mores e chefes do Serviço de Saúde ofereceram por diversas vezes recompensas em dinheiro em troca da simples possibilidade de observação da preparação e aplicação da terapêutica, de um registo do próprio segredo ou dos "livros de receitas" passados entre gerações de vaidyas. Já se viu atrás como Francisco Silva Torres e José António de Oliveira se dirigiram 
ao Governador-Geral da Índia em 1848. A Junta tinha tido conhecimento de curas "notáveis" realizadas por um desses curandeiros em Panjim, o Dessai Naná Tarangar. Sabendo-o na cidade, as autoridades procuraram o Dessai, prestando-se a entregar-lhe "um doente de medicina, e outro de cirurgia, com moléstias graves, de cura longa e difícil”. Então, escreveram Torres e Oliveira:

[o] curandeiro prontificou-se a curá-los; promete revelar-nos o segredo, depois de obtido o completo restabelecimento dos doentes; e apenas solicita uma recompensa pecuniária, arbitrada pela Junta de Saúde, quando porventura se obtenha um resultado feliz. Promete mais curar debaixo da nossa inspeção outras moléstias particulares a cada um dos sexos, as quais são neste país mui vulgares e incómodas. (Torres e Oliveira, 1871 [1848]: 42)

Para conseguir a obtenção deste e de outros segredos, Torres e Oliveira solicitaram fundos do tesouro provincial para auxiliar as pesquisas e recompensar o Dessai e outros curandeiros. Tal estratégia era vista como modo de construir um conhecimento público, rompendo as barreiras de um saber oculto e privado que encarecia o valor dos segredos; fazia com que se vendessem "a grandes preços", dizia-se (Torres e Oliveira, 1871 [1848]: 42). Estratégia semelhante parece ter sido adotada mais tarde, em 1879. Foi então planeado um inquérito (do qual, infelizmente, não se conhecem os resultados) à diversidade das medicinas de Goa, pelo chefe do Serviço de Saúde, Fonseca Torrie. O inquérito pretendia controlar a ação dos praticantes e a concessão de licenças, mas promovia igualmente a apropriação dos saberes indígenas, através de um levantamento dos processos e medicamentos que os praticantes usavam, dos meios pelos quais empregavam essas terapêuticas, da posse de segredos e da disposição para vendê-los ao Estado e por que quantia (Torrie, 1879).

O inquérito de Torres e Oliveira, de 1848, seria apenas divulgado à comunidade médica em 1871 por Gomes Roberto, que acompanhou a publicação do ofício das autoridades com uma nota de desalento: "Não nos consta haver-se obtido resultado algum favorável desta tentativa, nem de outras posteriormente feitas para se reconhecer a ação medicamentosa de certas plantas do país a que se atribuem fabulosas virtudes” (1871: 43). De facto, só no início do século xx parece haver notícia de maior impacto destas tentativas. Um evento exemplar deste "impacto" motivou especial atenção entre os investigadores de segredos e os entusiastas da botânica médica em Goa. Refiro-me ao celebrado caso dos segredos do Dehu (ou Deú) de Perném e ao entusiasmo em torno das pevides de bananeira 
brava como tratamento contra a varíola (sobre este caso, ver Roque, 2004). Ganhando um estatuto quase lendário, a história de Dehu Araundencar seria contada nas décadas seguintes, servindo de argumento e incentivo exemplar aos investigadores de segredos. Em 1916, perante o olhar vigilante de várias testemunhas, entre elas o autorizado Dr. Wolfango da Silva, lente da Escola Médica, o soldado reformado Dehu havia curado, com a sua pílula, e para espanto e contentamento dos presentes, a pneumonia do "velho conde de Maem, D. José de Noronha”, deixando impotente, na situação, o seu competidor direto Wolfango da Silva, cujos esforços falhavam na cura da moléstia (Souza, 1944: 57-58). O feito de Dehu mereceu a gratidão e generosidade do conde e sua família, que o terão recompensado com "pulseiras de oiro". A experiência terapêutica, aliás, terá acontecido no seguimento da promessa de concessão de uma pensão vitalícia a Dehu, caso este provasse a cura perante a direção do Serviço de Saúde (então chefiada por Wolfango da Silva). A recompensa surgiria, conforme se escreveu no ofício de 1916 que instituía a negociação, "em troca da cessão a favor do Estado de drogas indígenas, denominadas segredos, que [Dehu Araundencar] pretende possuir [...] caso se venha a reconhecer que tais drogas efetivamente têm as virtudes terapêuticas apontadas" (Silva, 1916: 8).

O caso de Dehu teve foros de vitória do programa de investigação dos segredos por intermédio de negociação direta entre praticantes indígenas e a direção do Serviço de Saúde. "Comprar" segredos usando recursos do Estado (ou até particulares) era, portanto, estratégia habitual de negociação com os praticantes para aceder a esse mundo fechado aos olhos dos médicos ocidentais. Pelo que, pela mesma altura, não espantariam as "avultadas somas de dinheiro" gastas pelo médico Filipe Neri Correia para obter as receitas e remédios hindus com que os "saudosos médicos ayurvédicos" Subraia Naique e Padre David Pereira eram ditos realizar as suas "maravilhosas curas" (Correia, 1925: i-iv). Casos poderá ter havido, porém, de ofertas ou concessões voluntárias de saberes e conhecimentos médicos indígenas. António Gomes Roberto, em 1863, por exemplo, dava a conhecer aos seus leitores um texto oferecido por Suriagi Ananda Rau, "traduzido de uma obra escrita em marata" com receitas e curativos atribuídos ao famoso médico hindu Xaranghdar, através das quais, dizia, "se conhece o diagnóstico e tratamento que nas suas doenças seguem os médicos gentios" (Roberto, 1863: 77-78).

\section{Conclusão}

Neste texto explorei a história de um campo de pesquisa: a botânica médica em Goa, entre meados do século XIX e as primeiras décadas do século XX. 
Pretendi, em primeiro lugar, tornar visível um domínio de práticas de conhecimento que tem vivido oculto ou à sombra de um dos mais ilustres ícones desse mesmo campo: Garcia de Orta e o seu Colóquio dos simples. Em segundo lugar, procurei caracterizar esse campo como estando assente numa dinâmica de descrição e transformação de segredos e plantas medicinais, propondo a ideia de "orientalismo de tradução". Sugeri que a afirmação profissional daqueles treinados na Escola de Goa assentava num programa de tradução orientado, a um tempo, para a apropriação de plantas e segredos e para a exclusão de praticantes de medicinas indianas com vista à afirmação da autoridade profissional dos praticantes da Escola Médica de Goa. Esta dupla estratégia de tradução assentava na delimitação de uma fronteira que poderia ser cruzada apenas por objetos (certas plantas e certos segredos) enquanto aos sujeitos - os praticantes da medicina indiana - era negada a entrada. Juntei ainda ao mecanismo desta dinâmica de inclusão, exclusão e demarcação um outro ingrediente: as táticas de captação de praticantes indígenas de modo a conseguir o acesso aos conhecimentos secretos dos vaidyas hindus.

Este ensaio exploratório suscita uma interrogação suplementar. O caso dos materiais de Goa contrasta com a excessiva ênfase que a literatura acerca da relação entre medicina e colonialismo coloca por vezes no carácter "hegemónico" e na "atitude de superioridade" da medicina ocidental perante outras formas de saber, nomeadamente a partir do último quartel do século XIX. Em Goa, durante o século XIX e o início do século $\mathrm{xx}$, as transações entre botânica médica e saberes nativos eram indício da incerteza e ambiguidade que prevaleciam nas relações de poder e conhecimento entre médicos "coloniais" (categoria que podia incluir nativos de Portugal assim como nativos de Goa) e médicos "indígenas". Esta incerteza passava ora por uma atitude de perseguição face à ameaça do curandeirismo, ora por uma atitude de descoberta focada na exploração das "maravilhas" das plantas e segredos medicinais indianos com o intuito de os resgatar para o conhecimento ocidental. Isto remete porventura para um reequacionamento do conhecimento orientalista enquanto simples processo autocentrado e autorreprodutivo, pelo menos no campo da botânica. A ideia de orientalismo de tradução em Goa incentiva, ao invés, a explorar o conhecimento colonialista das coisas e dos saberes do Oriente enquanto dinâmica que simultaneamente inclui, exclui e transforma elementos da alteridade nativa para, em seguida, os recriar no interior dos saberes ocidentais. Traduções coloniais transformam não só o que é apropriado, mas afetam e transformam o espaço epistémico e técnico daqueles que apropriam. É porventura nas dinâmicas da tradução 
científica, e não tanto na construção de um sistema orientalista que apenas reflete modelos ocidentais e abafa a alteridade, que importará doravante situar a compreensão das relações entre formas de conhecimento médico no "encontro colonial".

Revisto por Victor Ferreira

\section{Referências bibliográficas}

Almeida, Onésimo Teotónio (1999), "Nota de apresentação”, in Steven Shapin (org.), A revolução científica. Lisboa: Difel, I-XL.

Andrade, Lencastre Pereira de (1895), Os quatro champés - Estudos botanico-pharmacologicos da flora de Goa. Margão: Tip. das Ortigas.

Andrade, Lencastre Pereira de (1899), Plantas medicinais de Goa-sua bistória, descripção, analyse chimica, usos therapeuticos, economicos, etc. - com uma introdução bistórica. Bastorá: Tip. Rangel.

Andrade, Lencastre Pereira de (1929), "Plantas medicinais de Goa”, Boletim da Agência Geral das Colónias, 52, 39-52.

Arnold, David (1993), Colonizing the Body: State Medicine and Epidemic Disease in Nineteenth-Century India. Berkeley: University of California Press.

Barcar, Bascolá Mablá Dinay (1912), "A medicina aryana”, Boletim Geral de Medicina e Farmácia, 1, 55-62.

Barreto, J. Rafael dos Remédios (1948), "Plantas medicinais de Goa”, Boletim Geral das Colónias, XxIv(278-279), 68-90.

Bastos, Cristiana (2001a), "Um centro subalterno?: a Escola Médica de Goa e o império”, in Cristiana Bastos; Miguel Vale de Almeida; Bela Feldman-Bianco (orgs.), Trânsitos coloniais: diálogos críticos luso-brasileiros. Lisboa: Imprensa de Ciências Sociais, 133-49.

Bastos, Cristiana (2001b), "Doctors for the Empire: The Medical School of Goa and Its Narratives”, Identities, 8(4), 517-548. DOI: https://doi.org/10.1080/10702 89X.2001.9962707.

Bastos, Cristiana (2007a), "Medicina, império e processos locais em Goa, século XIX”, Análise Social, 182, 99-122.

Bastos, Cristiana (2007b), "Medical Hybridisms and Social Boundaries: Aspects of Portuguese Colonialism in Africa and India in the Nineteenth Century", Journal of Southern African Studies, 33(4), 767-782. DOI: https://doi.org/10.1080/03057070701646878.

Bayly, Christopher Alan (1996), Empire and Information. Intelligence Gathering and Social Communication in India, 1780-1870. Cambridge: Cambridge University Press.

Cardoso Jr., João (1902), Subsídios para a materia medica e therapeutica das possessões ultramarinas portuguezas. Tomo I. Lisboa: Tip. Academia Real das Ciências. 
Carvalho, Teresa Nobre de (2013), "Local Knowledge in Portuguese Words: Oral and Manuscript Sources of the Colloquies on the Simples by Garcia de Orta", HoST - Journal of History of Science and Technology, 8, 13-28.

Carvalho, Teresa Nobre de (2015), Os desafios de Garcia de Orta: Colóquios dos simples e drogas da Índia. Lisboa: Esfera dos Livros.

Clúsio, Carlos (1964), Aromatum et simplicium aliquot medicamentorum apud indos nascentium historia. Versão portuguesa do epítome latino dos Colóquios dos simples de Garcia de Orta. Lisboa: Junta de Investigações do Ultramar.

Correia, Filipe Neri (1925), Medicina indígena. Mais de mil e quinhentos específicos coligidos por Filipe Neri Correia. Margão: Tip. "Nacional” Editora.

Costa, Palmira Fontes da (org.) (2015), Medicine, Trade and Empire: Garcia de Orta's Colloquies on the Simples and Drugs of India (1563) in Context. London: Routledge.

Dalgado, Daniel Gelásio (1894), Classificação botânica das plantas e drogas descriptas nos "Colóquios da India". Bombaim: s.n.

Dalgado, Daniel Gelásio (1898), Flora de Goa e Savantvadi. Catalogo methodico das plantas medicinaes, alimentares e industriaes. Lisboa: Imprensa Nacional.

Dias, Miguel Caetano (1902), "Estado da Índia portugueza. Relatório do serviço de saúde referido ao anno de 1902”. Lisboa: Arquivo Histórico Ultramarino - Índia, Serviço de Saúde, maço 1988.

Ferrão, José Mendes (1992), A aventura das plantas e os descobrimentos portugueses. Lisboa: IICT/CNCMP/Fundação Berardo.

Ficalho, Conde de (org.) (1891), Colóquios dos simples e drogas da Índia por Garcia da Orta. Lisboa: Academia Real das Ciências.

Figueiredo, João Manuel Pacheco de (1960), "Escola Médico-cirúrgica de Goa: esboço histórico”, Arquivos da Escola Médico-Cirúrgica de Nova Goa, A(33), 119-237.

Gaitonde, Pundalik Dattatreya (1983), Portuguese Pioneers in India: Spotlight in Medicine. Mumbai: Popular Prakashan.

Gouveia, A. J. Andrade de (1985), Garcia d' Orta e Amato Lusitano na ciência do seu tempo. Lisboa: Ministério da Educação - Instituto de Cultura e Língua Portuguesa.

Gracias, Caetano Francisco Xavier (1898), Estudos botanico-therapeuticos da flora indigena. Os febrifugos e os antiperiódicos. Margão: s.n.

Gracias, Fátima da Silva (1994), Health and Hygiene in Colonial Goa, 1510-1961. Nova Deli: Concept Pub.

Henriques, Isabel Castro; Margarido, Alfredo (1989), Plantas e conbecimento do mundo nos séculos XVI e XVII. Lisboa: Alfa.

Latour, Bruno (1995), La science en action. Introduction à la sociologie des sciences. Paris: Folio.

Lei, Sean Hsiang-lin (1999), "From Changshan to a New Anti-malarial Drug: Re-networking Chinese Drugs and Excluding Chinese Doctors", Social Studies of Science, 29(3), 323-358. 
Leitão, Henrique; Sánchez, Antonio (2017), “Too Much to Tell: Narrative Styles of the First Descriptions of the Natural World of the Indies", History of Science, 55(2), 167-186. DOI: https://doi.org/10.1177/0073275317712864.

Leslie, Charles (1998), “The Ambiguities of Medical Revivalism in Modern India”, in Charles Leslie (org.), Asian Medical Systems: A Comparative Study. Deli: Motilal Banarsidass Publishers, 356-367.

Mathew, K. S. (1997), "The Portuguese and the Study of Medicinal Plants in India in the Sixteenth Century”, Indian Journal of History of Science, 32(4), 369-376.

Melo, Froilano de (1912), “Associação medico-cirurgica da India portugueza”, Boletim Geral de Medicina e Farmácia, 1, 75-76.

Mendes, António Lopes (1991), A Índia Portugueza. Breve descripção das possessões portuguezas na Ásia. Nova Deli/Madras: Asian Educational Services [ed. orig.: 1886].

Miranda, Manoel de (1911), "Chronica pelos cegos de Goa”, Boletim Geral de Medicina e Pharmacia, 7, 499-503.

Moacho, Matheus Rodrigues (1842), "Edital", Boletim do Governo do Estado da Índia, 56, 341-342.

Moura, João Herculano de (1872a), "Introdução”, Jornal de Pharmacia, Chimica e Historia Natural Medica, I(1), 1.

Moura, João Herculano de (1872b), "Duas palavras sobre o empirismo - Resposta às cartas que recebemos de dois colegas”, Jornal de Pharmacia Chimica e Historia Natural Medica, 11(I), 161-162.

Mukharji, Projit Bihari (2016), Doctoring Traditions: Ayurveda, Small Technologies, and Braided Sciences. Chicago: The University of Chicago Press.

Pignarre, Phillipe (1993), "Le médicament entre multiplicité et écart à l'idéal”, in Jean-Claude Beaune (org.), La philosophie du remède. Seyssel: Champ Vallon, 274-280.

Pinto, Viriato João (1887), Discurso inaugural proferido na sessão solene de abertura da Escola Medico-Cirúrgica de Nova Goa, aos 10 de julbo de 1887. S.l.: s.n.

Pinto, Viriato João (1909), "Plantas medicinaes da Índia”, O Oriente Portuguez, 11-12, 361-379.

Porter, Roy (1999), The Greatest Benefit to Mankind. A Medical History of Humanity. New York: W. W. Norton \& Company.

Roberto, António Gomes (1862), "Prospecto”, Jornal de Pharmacia e Sciencias Medicas da India Portugueza, I(1), 1.

Roberto, António Gomes (1863), "Medicina hindú”, Jornal de Pharmacia e Sciencias Medicas da India Portugueza, II(8), 77-78.

Roberto, António Gomes (1864), "Remedios peculiares da India Portuguesa, e suas applicações vulgares”, Archivo de Pharmacia e Sciencias Accesorias da India Portugueza, I(I), 5-7.

Roberto, António Gomes (1871), "Nota da redacção", Archivo de Pharmacia e Sciencias Acessorias da India Portugueza, 88, 43. 
Roque, Ricardo (2004), "Sementes contra a varíola: Joaquim Vás e a tradução científica das pevides de bananeira brava em Goa, Índia (1894-1930)", Manguinhos - História, Ciências, Saúde, 11(1), 183-222. DOI: https://doi.org/10.1590/ S0104-59702004000400010.

Sá, Aires Fernandes e (1920), "Valor terapêutico das garcínias", Boletim Geral de Medicina e Farmácia, 38-40.

Said, Edward (2004), Orientalismo. Lisboa: Cotovia [ed. orig.: 1978].

Sangwan, Satpal (1992), "Natural History in Colonial Context: Profit or Pursuit? British Botanical Enterprise in India, 1778-1820", in Patrick Petitjean; Catherine Jami; Anne Mari Moulin (orgs.), Science and Empires: Historical Studies about Scientific Development and European Expansion. Dordrecht: Kluwer Academic Press, 281-298.

Silva, Wolfango da (1916), "Sobre o emprego das drogas indígenas", Boletim Sanitário do Estado da Índia, setembro, 8.

Souza, João Chrysostomo d'Egipsy (1944), "Catálogo botânico das plantas de Goa e terras vizinhas”, Boletim do Instituto Vasco da Gama, 60, 54-196.

Teles, Manoel Galvão (1862), Observações sobre a história natural de Goa, feitas no anno de 1784 (publicadas por J.H. da Cunha Rivara). Nova Goa: Imprensa Nacional.

Torres, Francisco Maria da Silva (1846), “Ofício de 21/04/1846”, Lisboa: Arquivo Histórico Ultramarino - Índia, Serviços de Saúde, maço 1987.

Torres, Francisco Maria da Silva; Oliveira, José António (1871), "Investigação das plantas medicinais da India portugueza", Archivo de Pharmacia e Sciencias Acessorias da India Portugueza, 88, 41-42 [ed. orig.: 1848].

Torrie, João Stuart da Fonseca (1879), "Conhecimento do exercício ilegal de medicina e farmácia. 4 Março 1879”. Lisboa: Arquivo Histórico Ultramarino - Índia, Serviço de Saúde, maço 1983.

Walker, Timothy (2001), "Remedies from the Carreira da Índia: Asian Influences on Portuguese Medicine During the Age of Enlightenment”, Portuguese Studies Review, 9(1-2), 170-193.

Walker, Timothy (2010), "The Early Modern Globalization of Indian Medicine: Portuguese Dissemination of Drugs and Healing Techniques from South Asia on Four Continents, 1670-1830", Portuguese Literary and Cultural Studies, 17/18, 77-97.

Zimmermann, Francis (1989), Le discours des remèdes au pays des épices. Paris: Payot.

Zimmermann, Francis (1995), "The Scholar, the Wise Man, and Universals: Three Aspects of Ayurvedic Medicine", in Don Bates (org.), Knowledge and the Scholarly Medical Tradition. Cambridge: Cambridge University Press, 297-319. 
Artigo recebido a 04.12.2017

Aprovado para publicação a 20.03.2018

\section{Ricardo Roque}

Instituto de Ciências Sociais, Universidade de Lisboa

Av. Prof. Aníbal Bettencourt, n. ${ }^{\circ}$ 9, 1600-189 Lisboa, Portugal

Contacto: ricardo.roque@ics.ulisboa.pt

\section{The Wheat and the Chaff: Secrets and Medical Botany in Goa, c. $1840-1930$}

This article explores the dynamics of the research into and transformation of Indian vernacular medical knowledge by practitioners of Western-style medicine in Goa between 1840 and 1930. By describing the flourishing field of medical botany in this Portuguese colony, the article contributes to re-centering the histories of Portuguese medical orientalism, displacing its chronological focus from the sixteenth to the nineteenth century. It is argued that this orientalist research field in indigenous knowledge and plants was based on a strategy of scientific translation, both political and epistemic, with two connected orientations: the work of incorporation of indigenous medical-botanical knowledge (the so-called secrets) was followed by the political work of professional subordination and exclusion of the original indigenous practitioners.

Keywords: medical botany; orientalism; pharmacology; scientific translation.

\section{Le grain et l'ivraie: secrets et botanique médicale à Goa, c. $1840-1930$}

Dans cet article, nous nous penchons sur la dynamique de la recherche et de la transformation de savoirs médicaux vernaculaires indiens par des praticiens de la médecine occidentale à Goa entre 1840 et 1930. Par le truchement d'une description du domaine effervescent de la botanique médicale dans cette ancienne colonie portugaise, l'article contribue à un recentrement des histoires d'orientalisme botanique portugais en déplaçant l'approche chronologique du xvie siècle au XIXe siècle. Nous soutenons que ce domaine orientaliste sur des plantes et savoirs indigènes reposa sur une stratégie de traduction scientifique, à un temps sociopolitique et épistémique, accompagné de deux mouvements connexes: le travail d'incorporation de la connaissance médico-botanique indigène (les dénommés secrets) fut accompagné d'un travail politique de subordination et d'exclusion professionnelle de ses praticiens indigènes originaux.

Mots-clés: botanique médicale; orientalisme; pharmacologie; traduction scientifique. 